IJ§ER

ISSN: $2149-5939$
International Journal of Social Sciences and Education Research

Online, https://dergipark.org.tr/tr/pub/ijsser

Volume: 6(4), 2020

\title{
Paternity leave: A systematic review of studies in education and psychol- ogy from 1990-2019
}

\author{
Vahide Yigit Gencten ${ }^{1}$ and Emel Genc ${ }^{2}$
}

Received date: 23 / 09 / 2020

Accepted date: $12 / 11 / 2020$

\begin{abstract}
Paternity leave is integral to transition to parenting and father-children bonding, providing fathers the necessary time to take part in an equal share of household labour. Still, policy legislation on paternity leave from work for fathers is not prevalent; therefore, there exists no comprehensive review of their potential impacts and benefits to guide educational and psychological research in this area. This systematic review aims to acknowledge the extent to which different paternal leave for fathers is studied, focusing on the shifts in the trends of the inquiry of the fathers' leave based on time, study location, research context, and sampling by addressing this gap. Methods A systemic review of peer-reviewed literature retrieved from electronic databases was conducted. A total of 1993 abstracts were included for the study and selected 141 published papers from 1990 to 2019 on the use of paternal leave were reviewed. The main findings were coded and analysed through NVIVO 12. Results The synthesis of the results suggested that there has been growing interest in paid parental leave regarding fathers in particular over time. The findings showed that the focus was on the effects of paternity leave on the transition to parenting and gender equality.
\end{abstract}

Keywords: Paternal leave, paternity leave, parental leave, paid leave, fathers

\section{Introduction}

Parental leave policies are defined as the legislation for parents that permit employees to take time off work for pregnancy, birth, and adoption, personal illness, or care for family members, including children, parents, and spouses (Nandi, et al., 2018, p. 435). By 2013, all Organization for Economic Co-operation and Development (OECD) countries other than the United States offered some form of national paid leave policy for parents. For example, the range of parental leave is between 14 and 17 weeks, with pay at 100\% in developed countries such as Greece, Israel, the Netherlands, New Zealand, Spain, and Switzerland (OECD, 2016). In other countries, policymakers have also worked to increase women's labour force participation by facilitating work-life balance through childcare and parental leave policies (Burgess, Gregg, Propper, \& Washbrook, 2008, p. 169). However, those policies are still inadequate at satisfying the needs of fathers to involve in caregiving and household labour (Ruppander, 2010, p. 965); as a result, creating gender inequalities (Kotsadam \& Finseraas, 2011, p. 1611). Even though a shift in fathers' roles in children's lives can be observed in many cultures (O'Brien, Berit, \& Elin, 2007, p. 377) and men are not seen as solely breadwinners but responsible for sharing care with their partners; mothers are still acknowledged as the primary caregivers (Huerta, et al., 2014, p. 2). This might explain the reasons for unsatisfying policy arrangements for fathers. However, due to the influences of these

\footnotetext{
${ }^{1}$ Corresponding Author, PhD, Department of Preschool Teaching, Adiyaman University, College of Education, Adıyaman, Turkey, vyigit38@gmail.com ORCID ID:_0000-0003-0372-2298

${ }^{2} \mathrm{PhD}$, Department of Psychology, Bartın University, College of Literature, Bartin, Turkey, emelgenc@bartin.edu.tr, ORCID ID:_0000-0002-7921-3185
} 
Yigit Gencten, V., Genc, E. (2020). Paternity leave: A systematic review of studies in education and psychology from 1990-2019. International Journal of Social Sciences and Education Research, 6(4), 531-542

changes in gender roles in marriage in modern societies, research focus has shifted to the gendered division of household tasks and involvement of men in family life (Almqvist \& Duvander, 2014; Brady et al., 2017; Schober \& Zoch, 2018). Parenting roles that fathers recently were taken, and the responsibilities of employment also compel men to find a new balance in their lives (Johansson, 2011).

Many studies claim that family-friendly policies, particularly paternity leave-taking, is positively associated with father involvement in housework and care activities (e.g., Hosking, Whitehouse, \& Baxter, 2010; Tanaka \& Waldfogel, 2007). By having more time to spend at home, fathers also fulfil an active role in caring for the infants, helping them develop better bonds with their children (Almqvist \& Duvander, 2014; Brady et al., 2017). According to Rostgaard (2002, p. 344), by offering gender equality, paternal leave policies can encourage better relationships between children and fathers; therefore, advancing children's well-being outcomes. Furthermore, father leave policies can help mothers to return to their job and lead them to participate in the labour market; as a result of that, gender inequalities in labour force participation might be lessened (Nandi et al., 2018; Petts \& Knoester, 2018; Dearing, 2016). Based on Bratberg and Naz's (2014, p. 508) findings, there is also a relationship between fathers' use of paternity leave and the reduced use of mothers' sickness absence, leading to a change in the employers' notions about hiring women. On the other hand, job-protected paid leave policies can allow parents to contribute to household income and savings that may reduce the financial burden after a new-born comes to the family (Nandi et al., 2018, p. 436).

Positive father involvement brings great advantages to children (O'Brien, 2009; RomeroBaisas, 2015), to men as fathers (Smith, 2011), to the whole family (Cools, 2015; Rehel, 2014) and the society (Dermott, 2001). Despite the importance and growing attention to fathers' use of paternity leave, parental leave is such a rare case for many countries, and there is still significant variation in allowances and benefits and outcomes in different settings (Kaufman, 2017, p. 2). For instance; according to the latest OECD policy brief report (2016), only 12 OECD countries (i.e., Korea, Japan, France, Luxembourg, Portugal, Belgium, Iceland, Sweden, Norway, Finland, Germany, and Austria) offer at least two months of paid paternity leave that can only be taken by the father. Meanwhile, the UK, Australia, Denmark, Estonia, Poland, Slovenia, and Spain limit father-specific leave to two weeks (OECD, 2016). As seen from this variation and examples, the importance of paternal leave is not well understood by the authorities, and a considerable proportion of fathers still face obstacles and economic or social consequences for taking leave (Ray, Gornick, \& Schmitt, 2010, p. 197).

As indicated above, there is an upward trend about the inclusion of fathers to the parenting process through remediation of paternity policies; however, research on father involvement in parenting during pregnancy and after childbirth is insufficient. Contrary to European countries, developing countries such as Turkey have limited national paternity leave policy giving fathers the right to take paid time off work following a child's birth (Kurucirak \& Kulakac, 2014). Moreover, there is a lack of information and awareness on this issue within their contexts. As of our knowledge, this is one of the first studies on the fathers' parental leave comparing a range of countries involving developed, developing, and underdeveloped countries. Previous systematic review studies have mainly concentrated on the effects of paternity or parental leave on health outcomes, and none of them looked at fathers' leave from the point of psychology and education. Therefore, this review can lead us to understand what researchers in these areas mainly work on and the gaps in the literature to see what needs to be studied in the future. Thus, for this review, 
Yigit Gencten, V., Genc, E. (2020). Paternity leave: A systematic review of studies in education and psychology from 1990-2019. International Journal of Social Sciences and Education Research, 6(4), 531-542.

we summarise the evidence on the trends and focus of papers related to paternity leave delivered in different countries. Additionally, we examined the effects of paternity leave policies in various settings. Therefore, this systematic review aims to evaluate the empirical literature concerning the impacts of paternity leave and show the evidence for the necessity of fathers' leave.

\section{Methods}

Various methods have been utilised to capture paternity leave for fathers in various contexts to assess subjects related to father-child bonding, gender equality, the transition to fathering, the social and economic outcomes, and its relation to health issues. These different studies employ a wide range of methods in a variety of contexts and researching various topics in the fields of education and psychology; however, there are limited review studies to our knowledge that analyse the place of paternity leave in the world (e.g., Andres, Baird, Bingenheimer, \& Markus, 2016; Humphries et al., 2017; Nandi et al., 2018) and none of them looks for the nature of the papers in these disciplines. In this regard, we rely on that a more comprehensive review of existing studies on paternity leave in psychology and education can be conducted based on the specific titles, keywords, and abstracts. Accordingly, this review aims to carry out a thorough review of paternity leave to understand the shifts of studies on paternal leave policies over time, research context, sampling, and research settings that selected papers are placed through utilising a systematic review.

We began with analysis to form a frame for research on paternity leave policies by looking for the figures and trends based on time and study locations. In the following step, we analysed the selected papers in detail to present an understanding related to the methodology used in the articles, sample characteristics, and subject area. As our focus was to put paternity leave into a frame of the shift in existing literature over time regarding studies in psychology and education, we conducted this review to retrieve literature published in English using the databases ProQuest, PsycInfo, Web of Science, Science Direct, Medline, ERIC, British Education Index, and Education Research Complete from 1990 to 2019. Multiple search terms involved "paternity leave," parental leave," "paternal leave," "fathers leave," "family leave," and "paid leave" integrated with terms narrowing the searches to papers acknowledging the effect of these policies on paternal leave.

The inclusion criteria for the studies were to be published in peer-review journals and reported and evaluated the relationship between parental leave and father involvement. As we focused on specifically paternity leave for fathers and how it is approached in education and psychology, we did not analyse articles related to other fields such as those with medical outcomes. We also employed several criteria for exclusion. Initially, we excluded articles related to sickness-related absences from work, medical leave policies, maternity/maternal leave, and family illness, which did not take place in the scope of paternity leave. Then, we excluded theses/dissertations and nonpeer-reviewed or grey literature.

1993 articles were identified for a research title/abstract review on the final articles after removing duplicates, which, then, was followed by a full-text review to make the final decision for included articles (Figure 1). Those articles for the title/abstract review were assigned randomly to 2 reviewers for reliability purposes and decided papers for full-text review. Then, we reviewed full-text articles to clarify the title-abstract review and shared our arguments before concluding for inclusion and exclusion for the article. 
Yigit Gencten, V., Genc, E. (2020). Paternity leave: A systematic review of studies in education and psychology from 1990-2019. International Journal of Social Sciences and Education Research, 6(4), 531-542

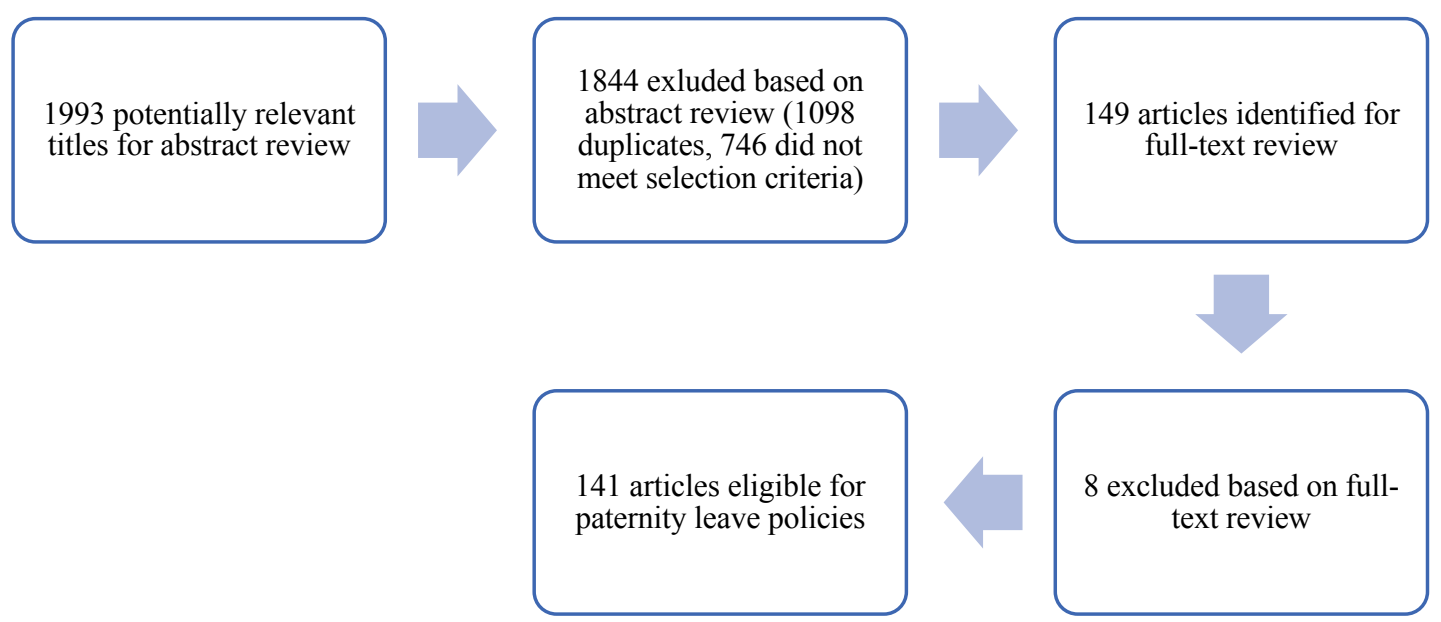

Figure 1. Article selection process

All eligible studies were classified into five groups: Years, countries, methodology, sampling, and subject area. They were then separated into subcategories through the NVIVO 12 program based on the similarities and differences of the codes extracted from the data. We divided the 'years' section into seven subgroups to draw a picture of variations of the number of papers in 5years periods: 1990-1994, 1995-1999, 2000-2004, 2005-2009, 2010-2014, and 2015-2019. 'Methodology' codes were classified as quantitative, qualitative, mixed methods, and review. When we finished analyzing the selected articles, we also gathered data sampling information in the chosen articles together, which then created groups as fathers, both parents, both parents and children, children, and others. Similarly, we finalised subject areas of the papers as the transition to parenting, gender equality, policy, financial issues, childcare, and others (reasons, the impact of education, religion, law, and employment).

\section{Findings}

The findings of the study were presented in two sub-sections. We begin with the bibliometric analysis of articles included in this review to form a frame for paternity leave, focusing on the shifts over time and study locations. The systematic review results were then discussed with particular attention given to sample characteristics who participated in the relevant studies or the focus of the research on these samples, subject areas, and methodology approached in those articles with a comprehensive understanding.

\subsection{Bibliometric results}

Bibliometrics, as a method for quantitative analysis, is applied to evaluate research performance, particularly journal articles (Cobo, Martinez, Gutierrez-Salcedo, Fujita, \& HerreraViedma, 2015). Hence, in this study, to produce a general overview of the phenomenon and acquire a better picture of the shifts in paternity leave research, the articles published in paternity or parental leave between 1990 and 2019 were included a bibliometric analysis. This would further lead to interpret how fathers' leave has been affected by the changes in laws, policies, and sociocultural positions in different cultures.

The existence of the papers related to parental leave for fathers varied across time. The interest in researching paternity leave developed after 2006. This presentation by years is to be potentially promising. Paternity leave or parental leave for fathers has become a prominent subject in 
Yigit Gencten, V., Genc, E. (2020). Paternity leave: A systematic review of studies in education and psychology from 1990-2019. International Journal of Social Sciences and Education Research, 6(4), 531-542.

psychology and education, especially over the last decade. When we look at Figure 2, which shows the number of articles produced in years, it can be noted that the interest in fathers' leave began to increase from 2006. This rise might be related to the emergence of parental leave in many countries happening much later than maternity leave, which was merely for women workers. For instance, the European Union recognised parental leave - for both parents - by 1996, despite the UK's opposition (Kamerman \& Moss, 2009, p. 2). Besides, this rise might be explained with the enhancement of the legislation. Australia can be seen as an illustration of this legislation developed in 2005 with the Family Provisions Test Case, which provides employees with a variety of 'new' rights such as shifting 52 weeks of unpaid leave to 2 years and the implementation of 8 weeks parental leave for both mothers and fathers to use simultaneously (Brennan, 2009, p. 21). Thus, it was essential to look at the countries in these papers published individually to comprehend the varied number of articles.

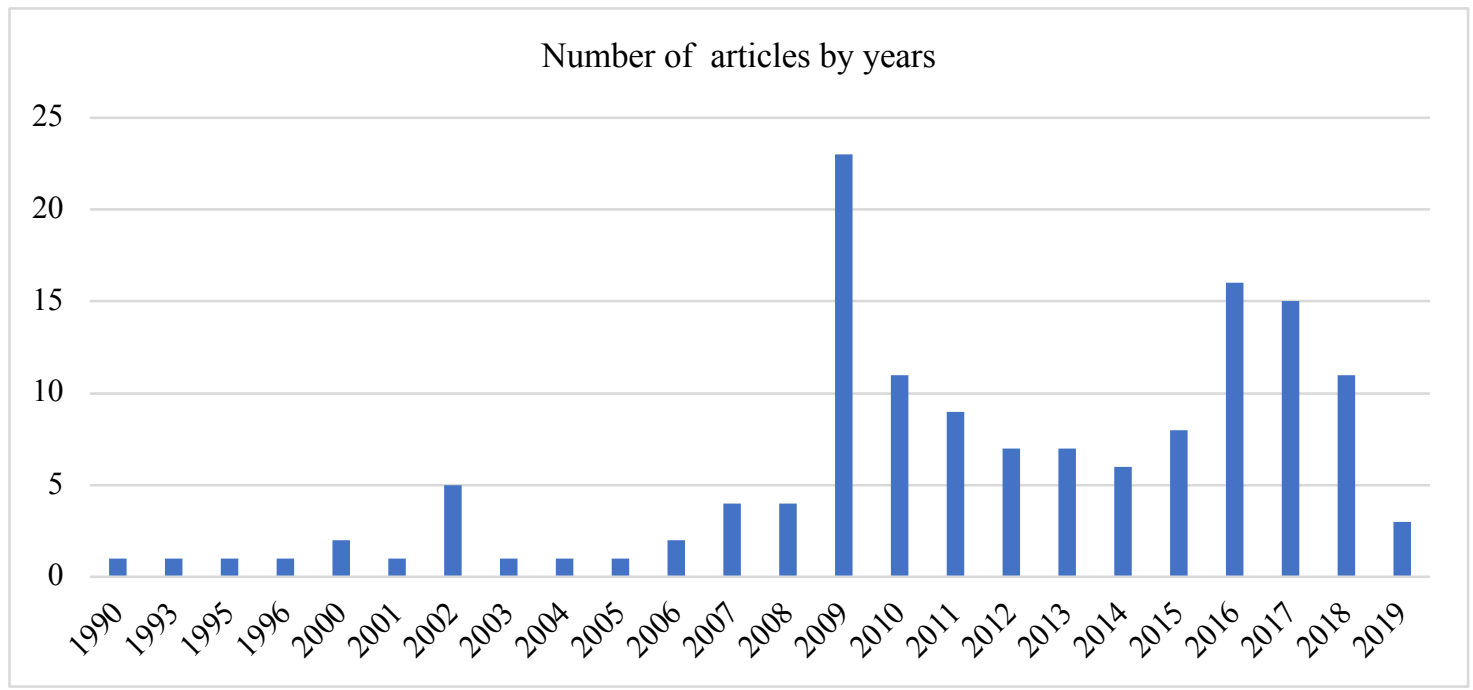

Figure 2. Number of articles (1990-2019)

Study locations were disclosed through the coding of all settings in selected articles related to parental or paternity leave. Looking at Figure 3, it is apparent that paternity leave gains importance worldwide, ranging from more developed countries such as Sweden and the US A to developing countries such as Nigeria. Researchers' interest might be more visible in countries where policy supports fathers' leave and protect their jobs when they are on leave since fathers tend to use paternity and parental leave more when they are well-paid (O'Brien \& Moss, 2010). It can be regarded from the analysis that a substantial number of papers originated from the United States, Sweden, and the UK, followed by Norway and Canada. Although these results represent an emerging trend in paternity leave, papers examined for this review show the researchers' attention on this topic, particularly comparing different arrangements for fathers and parents in different countries to suggest a beneficial policy for both parents and children. Among those countries, Sweden was the first to allow fathers to take paid paternity leave in 1974, which directly impacted issues such as gender equality, facilitating transmission to parenting and childcare (Mansdotter, Fredlund, Hallqvist, \& Magnusson, 2010). In contrast, the United States is one of the few countries throughout the world in which even mothers are ineligible for paid leave after childbirth (Zagorsky, 2017). However, it is essential to show that even in leading countries for applying paternal leave policies, more research on this topic needs to be undertaken to assess the outcomes of those policies. 
Yigit Gencten, V., Genc, E. (2020). Paternity leave: A systematic review of studies in education and psychology from 1990-2019. International Journal of Social Sciences and Education Research, 6(4), 531-542

Total number of articles produced in countries

$$
\text { Turkey }
$$

The U.S.A., Canada and several European countries

The U.S.A.

The U.S.A and the U.K.

The U.S.A

The U.K.

Switzerland

Sweden and the U.S.A

Sweden and the U.K.

Sweden and Poland

Sweden and Finland

Sweden

Spain and France

Spain

Southern African Countries

South Africa

Scandinavia

Republic of Ireland

Quebec and North America

Portugal and Spain

Portugal

Poland and Sweden

OECD Countries

Norway and Poland

Norway

Nordic countries Nigeria

Netherlands

Luxembourg Japan

Ireland

Iceland

Hungary and Slovenia

Germany, Austria and Switzerland

Germany

France and the U.K.

France and Sweden

France

Finland

Europe

Estonia

Eastern Europe

Denmark

Czech Republic

Canada and Quebec

Canada

Bangladesh, Cambodia, China, Indonesia, Papua.

Australia and Britain

Australia

Affluent countries

29 Countries

24 countries
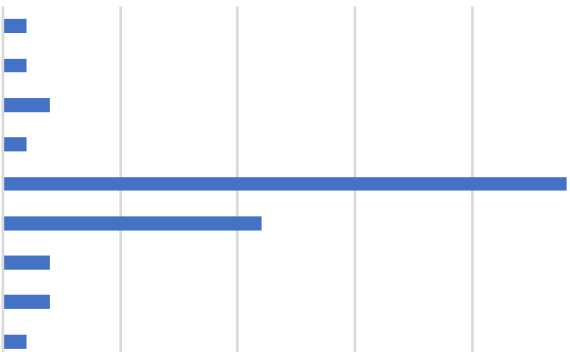

-

-
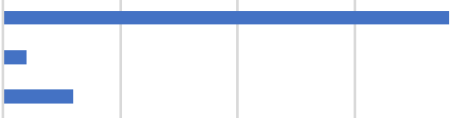

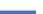
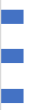

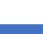

-

-

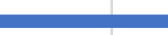

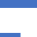

-

-

-
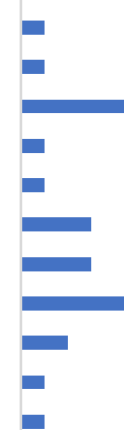

-
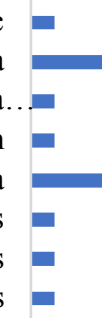

Figure 3. Total number of articles produced in countries 
Yigit Gencten, V., Genc, E. (2020). Paternity leave: A systematic review of studies in education and psychology from 1990-2019. International Journal of Social Sciences and Education Research, 6(4), 531-542.

\subsection{Systematic review results}

Table 1 provides the results obtained from a more detailed analysis of articles selected for this review by illustrating the time period of different categories of methodology, sample characteristics, and subject area. What stands out in the table is that there is only a minor difference in using the methods in researching paternity leave except for mixed-methods. However, the scope of the article was the investigation of the trends related to fathers' leave in the fields of education and psychology; therefore, illustrating a limited research area does not reflect a preference for one specific method.

Table 1 . The findings of systematic review based on the content

\begin{tabular}{|c|c|c|c|c|c|c|c|}
\hline & Total & $90-94$ & $95-99$ & $00-04$ & $05-09$ & $10-14$ & $15-19$ \\
\hline \multicolumn{8}{|l|}{ Methodology } \\
\hline Review & 41 & - & - & 4 & 17 & 13 & 7 \\
\hline Quantitative & 56 & 1 & 2 & 4 & 11 & 18 & 20 \\
\hline Qualitative & 38 & - & - & 1 & 6 & 7 & 24 \\
\hline Mixed Method & 6 & 1 & - & 1 & - & 2 & 2 \\
\hline \multicolumn{8}{|l|}{ Sample characteristics } \\
\hline Fathers & 80 & 1 & - & 5 & 13 & 21 & 40 \\
\hline Both parents & 50 & 1 & 2 & 4 & 20 & 12 & 11 \\
\hline Both parents and children & 3 & & - & - & - & 3 & - \\
\hline Children & 5 & - & - & 1 & - & 3 & 1 \\
\hline $\begin{array}{r}\text { Others (Academics, Stu- } \\
\text { dents, Managers Etc.) }\end{array}$ & 3 & - & - & - & 1 & 1 & 1 \\
\hline \multicolumn{8}{|l|}{ Subject Area } \\
\hline Transition to parenting & 45 & - & - & 4 & 7 & 12 & 22 \\
\hline Gender equality & 29 & 1 & - & - & 7 & 6 & 15 \\
\hline Policy & 37 & 1 & 2 & 2 & 15 & 9 & 8 \\
\hline Financial issues & 13 & - & - & 1 & 3 & 6 & 3 \\
\hline Childcare & 8 & - & - & 2 & 1 & 4 & 1 \\
\hline $\begin{array}{l}\text { Others (Reasons, the Im- } \\
\text { pact of Education, Reli- } \\
\text { gion, Law, Employment) }\end{array}$ & 9 & - & - & 1 & 1 & 3 & 4 \\
\hline
\end{tabular}

As the following step, after the completion of the analysis based on the trends in used methodology, we looked for sample characteristics in related papers. These sample characteristics were either those who participated in the studies or whom the review papers depended on (the intended audience). However, in some policy papers, there were no specific groups referenced; indeed, in some studies, the intended audience was broad such as politicians, fathers, parents, lawyers, and they discussed paternal leave in general without any particular references. Therefore, we put these research sampling into the closest one in the sample characteristics group or the 'others' categorisation. For instance, if the article discusses paternity leave from the point of lawyers, we reviewed the whole paper to look for whether it relies on fathers or both parents: paternity leave or parental leave. Based on this analysis of sample characteristics, it is revealed that the papers primarily were based on fathers' perceptions, their experiences, and how they interpret the period to become a father as expected. This trend gradually increased over time, beginning in earlier research in the 1990s till 2019. It is followed by the studies related to both parents -mothers and fathers- and a few studies were interested in children's experiences and others such as academics, students, or managers. Perhaps, the most interesting aspect of this is that although we selected papers from educational and psychological journals and studies, almost $3 \%$ of studies looked for the relationship between paternity leave and its effects on children. This is an unexpected result meaning that there needs to be more research on this subject. 
Yigit Gencten, V., Genc, E. (2020). Paternity leave: A systematic review of studies in education and psychology from 1990-2019. International Journal of Social Sciences and Education Research, 6(4), 531-542

In the final part of the systematic analysis of selected papers, we looked for the aims of the studies and identified subject areas. We concluded with six categories under this theme and a separate class named 'others' to identify those that did not fit into any groups. The first and most studied category was revealed as 'transition to parenting,' related to the papers based on fatherchildren relationships and fathers' transition to becoming a parent. The proportion of the articles falling into this category gradually increased by this time. Gender equality, as the second subject area, was mostly based on the perception of fathers' and mothers' roles in the household and childcare along with fathers' bonding with their children. Table 1 above shows that the interest in the relationship between paternal leave and gender equality gradually increased, similar to the transition to parenting. Policy reviews and articles related to the policy area were categorised as the third group, and policy research increased until 2014; a small decrease can be seen in Table 1 after this date. The relationship between paternal leave and financial factors, childcare, law, and others did not get attention as much as the first three categories in education and psychology.

\section{Discussion and conclusion}

Based on our findings, the majority of papers on paternity leave were published in the U.S.A., Sweden, and the UK, followed by Norway and Canada. According to Petts et al. (2018), fathers in the US A do not have a right to paid paternity leave assured by the laws. However, a large proportion of studies were conducted in the US A when compared with others. Although there might be several factors increasing fathers' involvement in housework and childcare activities such as extended women labour force, developing diversity in family, and shifts in attitudes towards employment and care activities (Huerta, et al., 2014), the substantial amount of research can be explained by the necessity of family-friendly leave policies for fathers in the USA. Considering economic conditions in the USA, which can be seen as advanced and their place as one of the most developed countries in the world (Shin, 2020), the reason for discussing the country's insufficient policies to meet parents' needs and to provide basic rights of workers who have a child or children becomes clear. Yet, there needs to be more studies in this field in order to lead the policymakers to act. On the other hand, there is a positive attitude in OECD countries where father-friendly arrangements for work and care have long been presented, beginning with Sweden (OECD, 2019).

According to Tanaka and Waldfogel (2007), family-friendly policies allow both parents to clear obstructions and maximise their parent-children bonding opportunities. Further arrangements for specifically fathers' leave are developed, which enables them to present around childbirth, observe their children's growing up and support them at this time, share responsibilities with mothers, and support women in housework (Rehel, 2014, p. 112). Our findings support these arguments by presenting the transition to parenting and gender equality as the most-researched subject areas in selected papers. The importance put on the transition to parenting shows a particular interest in the relationship between paternity leave and its strong connection to fatherhood, followed by 'gender equality.' Based on their study with 100 Australian fathers, Brady et al. (2017, p. 69) found that for fathers, spending the first six to eight months with their new-born child could boost their early paternal bonding. Also, Haas and Hwang (2008) conducted a study with fathers from large companies in Sweden. They found out that paternity leave enhances fathers' participation in childcare and their fulfilment with their relationship with children.

Fathers might still face some challenges they need to address once they use paternity leave (Doucet, 2009). To illustrate, being a father for the first time is a unique experience for fathers, and they may not know how to manage this new role (Reimer, 2017). Yet, mothers may have

Copyright (C) by International Journal of Social Sciences and Education Research ISSN: 2149-5939 
Yigit Gencten, V., Genc, E. (2020). Paternity leave: A systematic review of studies in education and psychology from 1990-2019. International Journal of Social Sciences and Education Research, 6(4), 531-542.

some expectations from the fathers such as sharing chores, responsibilities of new-born, and caring duties (Miller, 2013). In this case, parental leave policies influence parental behaviours for especially fathers who need to be more receptive to internalise parenting roles such as sharing duties with their partners in the house and child-related issues. Therefore, effective paternity leave policies lead to a natural consequence: promoting gender equality.

Finally, particularly, mothers' paid leave is supported in many countries (Kamerman S. B., 2005), except in the USA (Zagorsky, 2017); however, there is no specific regulations or a limited one for fathers' parental leave in many countries such as South Africa (Smit, 2011), Canada (Ball \& Daly, 2012), Japan (Nakazato, 2017), Israel (OECD, 2019) and Switzerland (Valarino \& Gauthier, 2016). For example, while in Europe, the average of paternal leave is about two weeks, in the Slovak Republic, there is no such right for parents (Gerbery, 2018). There was a lack of evidence about the role of the policies, and it is noticeable that all countries have their own policies (Karu \& Tremblay, 2017). Though this variation is argumentative, it is essential to consider the countries' culture, economic development, and social structure. It should be acknowledged that there are countries where women still face challenges with finding a place in working life (Sidani \& Al Hakim, 2012), and their main role is to take care of the household (Nicolete \& Almeida, 2018). Besides those developing countries, our study demonstrates that there are several studies related to the importance of parental leave as encouraging gender equality and fatherchildren relationship in a number of developed countries. However, only a few of these countries applied paid paternal leave policies for fathers. These results show us that paternal leave for fathers still needs to be developed. Furthermore, the role of fathers in childcare needs to be emphasised. As pointed out in previous studies, the fathers' role is important to early childhood (Lynch, 2019). However, there is a lack of studies on child education and their development, which can provide evidence to support the role of fathers leave on children's later academic lives.

\section{Limitations}

The findings discussed in this paper offered considerable insights about fathers' right to paternal leave and the development of research related to this area. We attended to frame a big picture of global studies. However, there are a few limitations that are common in systematic reviews. A great effort was made to ensure that mistakes were minimised, such as inaccurate classification of data or missing materials; from the beginning of the research as identifying keywords to search in databases and limiting databases to several ones; to the final part of discussing the findings. Yet, several factors should be considered for future research. Although the current study included search terms on father, paternity, and paternal leave, our findings claimed that mostly research combining fathers' leave with gender equality, transmission to parenting, and family policies. It was noticeable that there is a significant gap in the relationship between the influence of fathers' leave on whole family interaction, specifically children's social, emotional, psychological, and educational development. To obtain a clear picture of the relationship between fathers' leave and children's development, it might be beneficial to conduct more longitudinal studies. Additionally, relevant confounders (e.g., the number of siblings, the child's position in the family, and caregivers) should also be included to further elucidate this complicated relationship.

Supplementary Materials: The following are available online at https://osf.io/hwfuz/

\section{References}

Almqvist, A. L., \& Duvander, A. Z. (2014). Changes in gender equality? Swedish fathers' parental leave, division of childcare and housework. Journal of Family Studies, 20(1), 19-27. 
Yigit Gencten, V., Genc, E. (2020). Paternity leave: A systematic review of studies in education and psychology from 1990-2019. International Journal of Social Sciences and Education Research, 6(4), 531-542

Andres, E., Baird, S., Bingenheimer, J. B., \& Markus, A. R. (2016). Maternity Leave Access and Health: A Systematic Narrative Review and Conceptual Framework Development. Matern Child Health J, 20, 1178-1192.

Ball, J., \& Daly, K. (2012). Father Involvement in Canada: Diversity, Renewal, and Transformation. UBC Press.

Brady, M., Stevens, E., Coles, L., Zadoroznyj, M., \& Martin, B. (2017). 'You can Spend Time. . . But not Necessarily be Bonding with Them': Australian Fathers' Constructions and Enactments of Infant Bonding. Jnl Soc. Pol., 46(1), 69-90.

Brady, W. J., Wills, J. A., Jost, J. T., Tucker, J. A., \& Van Bavel, J. J. (2017). Emotion shapes the diffusion of moralised content in social networks. Proceedings of the National Academy of Sciences, 114(28), 7313-7318.

Bratberg, E., \& Naz, G. (2014). Does Paternity Leave Affect Mothers' Sickness Absence? European Sociological Review, 30(4), 500-511.

Brennan, D. (2009). Australia: the difficult birth of paid maternity leave. In S. B. Kamerman, \& P. Moss (Eds.), The politics of parental leave policies: Children, parenting, gender and the labour market (pp. 15-33). Bristol, UK: Bristol University Press.

Burgess, S., Gregg, P., Propper, C., \& Washbrook, E. (2008). Maternity Rights and Mothers' Return to Work. Labour Economics, 15, 168-201.

Cobo, M., Martinez, M. A., Gutierrez-Salcedo, M., Fujita, H., \& Herrera-Viedma, E. (2015). 25 years at Knowledge-Based Systems: A bibliometric analysis. Knowledge-Based Systems, 80, 3-13.

Cools, S. (2015). Causal Effects of Paternity Leave on Children and Parents. Scand. J. of Economics, 117(3), 801-828.

Corte-Rodriguez, M. D. (2018). Child-related leave and women's labour market outcomes: towards a new paradigm in the European Union? Journal of Social Welfare and Family Law, 40(3), 376-393.

Dearing, H. (2016). Gender equality in the division of work: How to assess European leave policies regarding their compliance with an ideal leave model. Journal of European Social Policy, 26(3), 234247.

Dermott, E. M. (2001). New Fatherhood in Practice?- Parental Leave in the UK International Journal of Sociology and Social Policy, 21(4/5/6), 145-164.

Doucet, A. (2009). Dad and Baby in the First Year: Gendered Responsibilities and Embodiment. The Annals of the American Academy of Political and Social Science, 624, 78-98.

Geisler, E., \& Kreyenfeld, M. (2011). ). Against all odds: Fathers' use of parental leave in Germany. Journal of European Social Policy, 21(1), 88-99.

Gerbery, D. (2018, 04). Leave Network. Retrieved 03 11, 2020, from https://www.leavenetwork.org/ fileadmin/user_upload/k_leavenetwork/country_notes/2018/FINAL.Slovakia2018.pdf

Haas, L., \& Hwang, P. (2008). The impact of taking parental leave on fathers' participation in childcare and relationships with children: Lessons from Sweden. Community, Work \& Family, 11(1), 85-104.

Hegewisch, A., \& Gornick, J. (2011). The impact of work-family policies on women's employment: A review of research from OECD countries. Work \& Family, 14(2), 119-138.

Hosking, A., Whitehouse, G., \& Baxter, J. (2010). Duration of Leave and Resident Fathers' Involvement in Infant Care in Australia. Journal of Marriage and Family, 72(5), 1301-1316.

Huerta, M. C., Adema, W., Baxter, J., Han, W. J., Lausten, M., Lee, R., \& Waldfogel, J. (2014). Fathers' Leave and Fathers' Involvement: Evidence from Four OECD Countries. European Journal of Social Security, 4(309-346), 16.

Humphries, L. S., Lyon, S., Garza, R., Butz, D. R., Lemelman, B., \& Park, J. E. (2017). Parental leave policies in graduate medical education: A systematic review. The American Journal of Surgery, 214, 634-639.

Johansson, T. (2011). Fatherhood in Transition: Paternity Leave and Changing Masculinities. Journal of Family Communication, 11(3), 165-180.

Copyright (C) by International Journal of Social Sciences and Education Research

ISSN: 2149-5939 
Yigit Gencten, V., Genc, E. (2020). Paternity leave: A systematic review of studies in education and psychology from 1990-2019. International Journal of Social Sciences and Education Research, 6(4), 531-542.

Kamerman, S. B. (2005). Maternity, Paternity, and Parental Leave Policies: The Potential Impacts on Children and Their Families. Encyclopedia on Early Childhood Development, 1-4.

Kamerman, S., \& Moss, P. (2009). The politics of parental leave policies: Children, parenting, gender and the labour market. Bristol, UK: Bristol University Press.

Karu, M., \& Tremblay, D. (2017). Fathers on parental leave: an analysis of rights and take-up in 29 countries. Community, Work \& Family, 1-19.

Kaufman, G. (2017). Barriers to equality: Why British fathers do not use parental leave. Community, Work \& Family, 21(3), 310-325.

Keck, W., \& Saraceno, C. (2013). The impact of different social-policy frameworks on social inequalities amon women in the European Union: The labour-market participation of mothers. Social Politics, 20(3), $297-328$.

Kotsadam, A., \& Finseraas, H. (2011). The state intervenes in the battle of the sexes: Causal effects of paternity leave. Social Science Research, 40, 1611-1622.

Kurucirak, S., \& Kulakac, O. (2014). The experiences and involvements of fathers during 4-12 months of their children's lives: a mixed method study. Turk J Public Health, 12(2), 113-126.

Lynch, J. (2019). Father Reflections on Their Involvement with Primary School Students: Connections to School Literacy Learning. Literacy Research: Theory, Method, and Practice, 68(1), 396-416.

Mansdotter, A., Fredlund, P., Hallqvist, J., \& Magnusson, C. (2010). Who takes paternity leave? A cohort study on prior social and health characteristics among fathers in Stockholm. Journal of Public Health Policy, 31(3), 324-341.

Melchiorsen, P. M. (2019). Bibliometric differences - a case study in bibliometric evaluation across SSH and STEM. Journal of Documentation, 75(2), 366-378.

Miller, T. (2013). Shifting out of neutral on parental leave. Public Policy Research, 19(4), 258-262.

Misra, J., Lundquist, J. H., \& Templer, A. (2012). ). Gender, work time, and care responsibilities among faculty. Sociological Forum, 27(2), 300-323.

Nakazato, H. (2017). Fathers on Leave Alone in Japan: The Lived Experiences of the Pioneers. In M. O'Brien, \& K. Wall (Eds.), Comparative Perspectives on Work-Life Balance and Gender Eqality (pp. 231-255). Life Course Research and Social Policies 6.

Nandi, A., Jahagirdar, D., Dimitris, M. C., Labrecque, J. A., Strumpf, E. C., Kaufman, J. S., . . Heymann, S. J. (2018). The Impact of Parental and Medical Leave Policies on Socioeconomic and Health Outcomes in OECD Countries: A Systematic Review of the Empirical Literature. The Milbank Quarterly, 96(3), 434-471.

Nicolete, J. N., \& Almeida, J. (2018). Women and education: Normalisation and professionalisation. Policy Futures in Education, 16(5), 576-588.

O'Brien, M. (2009). Fathers, Parental Leave Policies, and Infant Quality of Life: International Perspectives and Policy Impact. The Annals of the American Academy of Political and Social Science, 624, 190-213.

O'Brien, M., Berit, B., \& Elin, K. (2007). Fathers, Work and Family Life. Community, Work and Family, 10(4), 375-386.

O'Brien, M., \& Moss, P. (2010). Fathers, Work and Family Policies in Europe. In M. E. Lamb, Th e Role of the Father in Child Development (pp. 551-577). New York, NY: Wiley.

OECD. (2016, March). OECD Policy Brief. Retrieved 12 04, 2019, from https://www.oecd.org/policybriefs/parental-leave-where-are-the-fathers.pdf

OECD. (2019). OECD: Better Policies for Better Lives. Retrieved 12 09, 2019, from http://www.oecd.org/els/family/database.htm

Pelletier, A. (2006). Family Medical Leave Act of 1993-Why Does Parental Leave in the United States Fall so Far behind Europe. Gonzaga Law Review, 42(3), 547-576.

Petts, R. J., \& Knoester, C. (2018). Paternity Leave-Taking and Father Engagement. Journal of Marriage and Family, 80(5), 1144-1162.

Copyright $(\mathcal{C}$ by International Journal of Social Sciences and Education Research

ISSN: $2149-5939$ 
Yigit Gencten, V., Genc, E. (2020). Paternity leave: A systematic review of studies in education and psychology from 1990-2019. International Journal of Social Sciences and Education Research, 6(4), 531-542

Petts, R. J., Knoester, C., \& Li, Q. (2018). Paid paternity leave-taking in the United States. Community, Work \& Family, 1-22.

Petts, R. J., Knoester, C., \& Waldfogel, J. (2019). Fathers' Paternity Leave-Taking and Children's Perceptions of Father-Child Relationships in the United States. Sex Roles, 1-16.

Ray, R., Gornick, J. C., \& Schmitt, J. (2010). Who cares? assessing generosity and gender equality in parental leave policy designs in 21 countries. Journal of European Social Policy, 20(3), 196-216.

Rehel, E. M. (2014). When Dad Stays Home Too: Paternity Leave, Gender, and Parenting. Gender \& Society, 28(1), 110-132.

Reimer, T. (2017). Measuring German Fathers' Involvement in Childcare. Men and Masculinities, 20(5), 588-608.

Romero-Baisas, P. (2015). Consequences Paternity Leave on Allocation of Childcare and Domestic Tasks. Revista Española de Investigaciones Sociológicas, 149, 87-108.

Rostgaard, T. (2002). Setting time aside for the father: father's leave in Scandinavia. Community, Work and Family, 343-364.

Ruppander, L. (2010). Cross-national reports of housework: an investigation of the gender empowerment measure. Social Science Research, 39(6), 963-975.

Schober, P. S., \& Zoch, G. (2018). Change in the gender division of domestic work after mothers or fathers took leave: exploring alternative explanations. European Societies, 21(1), 158-180.

Shin, I. (2020). Learning advanced technology in easier ways from developed countries. Journal of Economics and Finance, 44, 120-139.

Sidani, Y., \& Al Hakim, Z. (2012). Work-family conflicts and job attitudes of single women: a developing country perspective. International Journal of Human Resource Management., 23(7), 1376-1393.

Smit, R. (2011). Family-Related Policies in Southern African Countries: Are Working Parents Reaping Any Benefits? Journal of Comparative Studies, 42(1), 15-36.

Smith, A. (2011). Working Fathers in Europe: Earning and Caring. European Sociological Review, 27(2), $230-245$

Tanaka, S., \& Waldfogel, J. (2007). Effects Of Parental Leave And Work Hours On Fathers' Involvement With Their Babies. Community, Work \& Family, 10(4), 409-426.

Valarino, I., \& Gauthier, J. (2016). Paternity leave implementation in Switzerland: a challenge to gendered representations and practices of fatherhood? Community, Work \& Family, 19(1), 1-20.

Zagorsky, J. L. (2017). Divergent Trends in US Maternity and Paternity Leave, 1994-2015. AJPH RESEARCH, 107(3), 460-465.

\section{Compliance with Ethical Standards}

Ethical Standard: This paper complies with the duplicate and piecemeal publication of data guidelines outlined in the $6^{\text {th }}$ edition Publication Manual of the American Psychological Association as well as any and all Sex Roles provisions related to "alerting the editor."

\section{Data Availability Statement}

The data that supports the findings of this study are available in the supplementary material of this article.

Electronic supplementary material: https://osf.io/hwfuz/ (PDF $192 \mathrm{~Kb}$ )

Disclosure of Potential Conflicts of Interest: There are no potential conflicts of interest (financial or nonfinancial).

Research Involving Human Participants and/or Animals: This research did not involve human participants or animals. 